\title{
Disaster Risk Mitigation for Forest and Land Fire Prevention in Sumatera
}

\author{
Tukiyat, F. Heru Widodo, R. Djoko Goenawan \\ Balai Besar Teknologi Modifikasi Cuaca (BBTMC) - BPPT, GEOSTECH \\ Kawasan PUSPIPTEK Serpong - Tangerang Selatan 15314, Indonesia. \\ tukiyat@bppt.go.id
}

Article History

accepted 31/08/2020

approved 22/09/2020

published 28/10/2020

\begin{abstract}
The phenomenon of forest and land fires (karhutla) in Sumatera always recurs every year. During the dry season, it is necessary to be aware of the emergence of hotspots and be addressed immediately before an actual fire occurs. This study aims to prevent the risk of forest and land fires by applying Weather Modification Technology (TMC). The application of TMC is intended to wet the land (rewetting) so that hotspots do not appear. The research was conducted in Riau, Jambi and South Sumatera Provinces. Research observations were carried out from May to June 2020. The results showed that TMC could increase the intensity of rainfall. The volume of rainwater produced for Riau is 44.1 million $\mathrm{m}^{3}$ and in Jambi and South Sumatera as much as 50.20 million $\mathrm{m}^{3}$. The rainfall that falls is expected to wet the peatlands and fill the peat domes so that TMAT (ground water level) is maintained and soil moisture is maintained. During the implementation of TMC, it was possible to keep the TMAT from dropping more than $40 \mathrm{~cm}$, even for some locations where the TMAT peat measurement had increased.
\end{abstract}

Keywords : Mitigation, Karhutla, Weather Modification Technology

\section{Abstrak}

Fenomena kebakaran hutan dan lahan (karhutla) di Sumatera selalu berulang setiap tahun. Pada musim kemarau perlu diwaspadai munculnya titik panas (hotspot) dan segera ditangani sebelum terjadi kebakaran yang masip. Penelitian ini bertujuan untuk pencegahan risiko bencana karhutla dengan penerapan Teknologi Modifikasi Cuaca (TMC). Penerapan TMC dimaksudkan untuk membasahi lahan (rewetting) agar tidak muncul hotspot. Penelitian dilakukan di Provinsi Riau, Jambi dan Sumatera Selatan. Pengamatan penelitian dilakukan pada bulan Mei sampai Juni 2020. Hasil penelitian menunjukkan bahwa TMC dapat meningkatan intensitas curah hujan. Volume air hujan yang dihasilkan untuk Riau sebanyak 44,1 juta $\mathrm{m}^{3}$ dan di Jambi dan Sumatera Selatan sebanyak 50,20 juta $\mathrm{m}^{3}$. Curah hujan yang turun diharapkan dapat membasahi lahan gambut dan mengisi kubah gambut agar terjaga TMAT (tinggi muka air tanah) dan menjaga kelembaban tanah. Selama penerapan TMC dapat menjaga TMAT tidak turun melebihi $40 \mathrm{~cm}$ bahkan untuk beberapa tempat lokasi pengukuran TMAT gambut mengalami peningkatan.

Kata kunci : Mitigasi, Karhutla, Teknologi Modifikasi Cuaca

Social, Humanities, and Education Studies (SHEs): Conference Series https://jurnal.uns.ac.id/shes
p-ISSN 2620-9284

e-ISSN 2620-9292 


\section{PENDAHULUAN}

Berdasarkan pada data BNPB (2019), bahwa selama sepuluh tahun terakhir, Indonesia telah mengalami karhutla sebanyak 1.226 kejadian (Databoks,2019). Kejadian karhutla tertinggi terjadi pada 2018 dan 2016 dengan masing-masing sebanyak 527 dan 178 kejadian. Karhutla pada 2019 meluas di sejumlah wilayah seperti Riau, Sumatera Selatan, Jambi, Kalimantan Selatan, Kalimantan Tengah, Kalimantan Barat, dan Kalimantan Timur. Indonesia mempunyai lahan gambut terbesar kedua di dunia dengan luas mencapai 22,5 juta hektar (ha), sedangkan urutan pertama ditempati oleh Brazil dengan luas lahan gambut sebesar 31,1 juta ha (Kata Data, 2019). Keberadaan lahan gambut tersebut mempunyai berbagai manfaat antara lain sebagai penyimpan carbon (30\%), mencegah kekeringan dan mencegah pencampuran air asin pada irigasi pertanian. Sehubungan dengan hal tersebut maka lahan gambut perlu dijaga kelestariannya tidak terjadi konversi lahan. Fenomena kebakaran hutan dan lahan (karhutla) di Sumatera khususnya di Riau, Jambi dan Sumatera Selatan selalu berulang setiap tahun. Pada musim kemarau maka perlu diwaspadai munculnya titik api (hotspot) dan segera ditangani sebelum terjadi titik hotspot yang masip. Muculnya karhutla di Sumatera terutama Riau terjadi dua periode musim kemarau dalam setahun yaitu antara Februari-April dan Juni-Oktober. Untuk memitigasi bencana karhutla di Sumatera maka siaga darurat pengendalian dan pencegahan karhutla dilakukan dengan koordinasi melalui strategi pentahelix. Mitigasi untuk mereduksi kebencanaan mitigasi bencana hidrometeorologi dilakukan melalui perencanaan dan dilakukan secara terintegrasi.

Perubahan iklim dapat meningkatkan frekuensi dan besarnya berbagai jenis peristiwa ekstrem, termasuk banjir, kekeringan, badai tropis, dan kebakaran hutan. BMKG memprediksi awal musim kemarau mulai berlangsung di sebagian wilayah Indonesia pada bulan April 2020 dan puncaknya pada bulan Agustus (https://tirto.id/eG9p). Mitigasi adalah upaya untuk mengurangi hilangnya nyawa dan properti dengan memperburuk dampak bencana. Dalam rangka untuk mitigasi menjadi efektif kita perlu mengambil tindakan sekarang-sebelum bencana berikutnya-untuk mengurangi konsekuensi manusia dan keuangan (menganalisis risiko, mengurangi risiko, dan mengasuransikan terhadap risiko). Mitigasi dibagi dalam dua hal yaitu mitigasi struktural dan mitigasi non struktural. Mitigasi struktural merupakan mitigasi yang berupaya untuk meminimalkan bencana yang dilakukan dengan cara membangun berbagai prasarana fisik dan menggunakan teknologi. Dalam konteks ini upaya yang dilakukan meliputi membangun waduk untuk mencegah banjir, membuat sekat kanal (kanalisasi), membangun EWS (Early Warning System) yang merupakan peringatan diri untuk memberitahukan kepada masyarakat apabila akan terjadi bahaya. Sedang mitigasi non struktural merupakan upaya untuk mengurangi dampak bencana melalui regulasi atau peraturan-peraturan, misalnya Undang-Undang Penanggulangan Bencana sebagai upaya non struktural dalam bidang kebijakan, pembuatan

Mitigasi Bencana hidrometeorologi selalu dilakukan karena bencana akan mengintai Indonesia pepanjang tahun yaitu pada bulan Desember - Februari terjadi banjir, tanah longsor, dan gelombang tinggi. Pada bulan Maret- Mei terjadi mitigasi bencana putting beliung, petir dan hujan es. Pada bulan Juni - Agustus terjadi bencana kekeringan, karhutla, gelombang tinggi. Pada bulan September - November mitigasi bencana putting beliung, petir dan hujan es. Siklus hidrometeorologi ini akan berulang dari tahun ke tahun.

Berdasar pada data BNPB, bahwa selama sepuluh tahun terakhir, Indonesia telah mengalami kebakaran hutan dan lahan (karhutla) sebanyak 1.226 kejadian. Kejadian karhutla tertinggi terjadi pada 2018 dan 2016 dengan masing-masing sebanyak 527 dan 178 kejadian. Karhutla pada 2019 meluas di sejumlah wilayah seperti Riau, Sumatera Selatan, Jambi, Kalimantan Selatan, Kalimantan Tengah, 
Kalimantan Barat, dan Kalimantan Timur (BNPB, 2019). Data matrik titik panas Terrea/Aqua (LAPAN) untuk level confidence > 80\% tahun 2020 menunjukkan bahwa luas kebakaran hutan dan lahan dalam kurun waktu Januari-September 2019 dengan luasan 620.201 hektar dan luasan ini naik dua kali lipat lebih besar dibandingkan ratarata kebakaran hutan sepanjang 2016-2018. Hasil monitoring yang dilakukan oleh KLHK samapai pada bulan Agustus 2020 jumlah hotsport yang ada di Provinsi Riau, Jambi dan Sumatera Selatan ada penurunan dibanding dengan tahun 2019 (Menlhk.go.id/hotspot/matrik_tahunan). Untuk menyelesaikan masalah tersebut perlu dilakukan secara terintegrasi dengan startegi pentahelix. Dalam konsep pentahelix ini semua elemen bergerak dalam rangka untuk mitigasi bencana. Adapun stakeholder yang terlibat dalam pentahelix meliputi unsur pemerintah, pelaku usaha, dunia pendidikan (Akademisi), masyarakat dan media. Kelima peran ini berkolaborasi sedemikian rupa sehingga masing-masing dapat menjalankan fungsi sesuai dengan perannnya.

Tujuan utama dilakukan mitigasi risiko bencana karhutla dengan penerapan teknologi TMC dimaksudkan untuk membasahi lahan gambut agar terjaga kelembaban air tanah dan untuk meminimalkan kerusakan sumberdaya alam, khususnya SDA hutan dan lahan di Sumatera, khususnya di Provinsi Riau, Jambi dan Sumatera Selatan. Hal ini sejalan dengan pasal 1 ayat 6 PP 21 tahun 2008 tentang Penyelenggaraan Penanggulangan Bencana, mitigasi bencana merupakan sebuah rangkaian upaya guna mengurangi risiko bencana, baik lewat pembangunan fisik atau penyadaran dan peningkatan kemampuan dalam menghadapi ancaman bencana. Secara umum mitigasi merupakan upaya mengurangi risiko bencana (baik bencana alam alias natural disaster maupun bencana ulah manusia alias man-made disaster), sehingga jumlah korban dan kerugian bisa diperkecil.

\section{METODE}

Penelitian ini menggunakan metode kualitatif dengan model analisis deskriptif. Metode deskriptif dimasudkan untuk mendeskripsikan fenomena yang terkait dengan pencegahan kebakaran hutan dan lahan. Obyek dan ruang lingkup penelitian meliputi aspek curah hujan, titik panas (hotspot), tinggi muka air tanah lahan gambut, dan parameter cuaca yang terkait dengan kegiatan teknologi modifikasi cuaca. Metode pengumpulan data dilakukan melalui observasi dan hasil pengukuran data curah hujan di provinsi Riau, Jambi dan Sumatera Selatan. Penelitian dilakukan selama periode kegiatan Teknologi Modifiaksi Cuaca di Sumatera pada bulan Mei dan Juni 2020. Posko kegiatan ditempatkan di Provinsi Riau dan Sumatera Selatan. Berikut ini merupakan peta kerja pelaksanaan TMC di Sumatera (lihat Gambar 1).

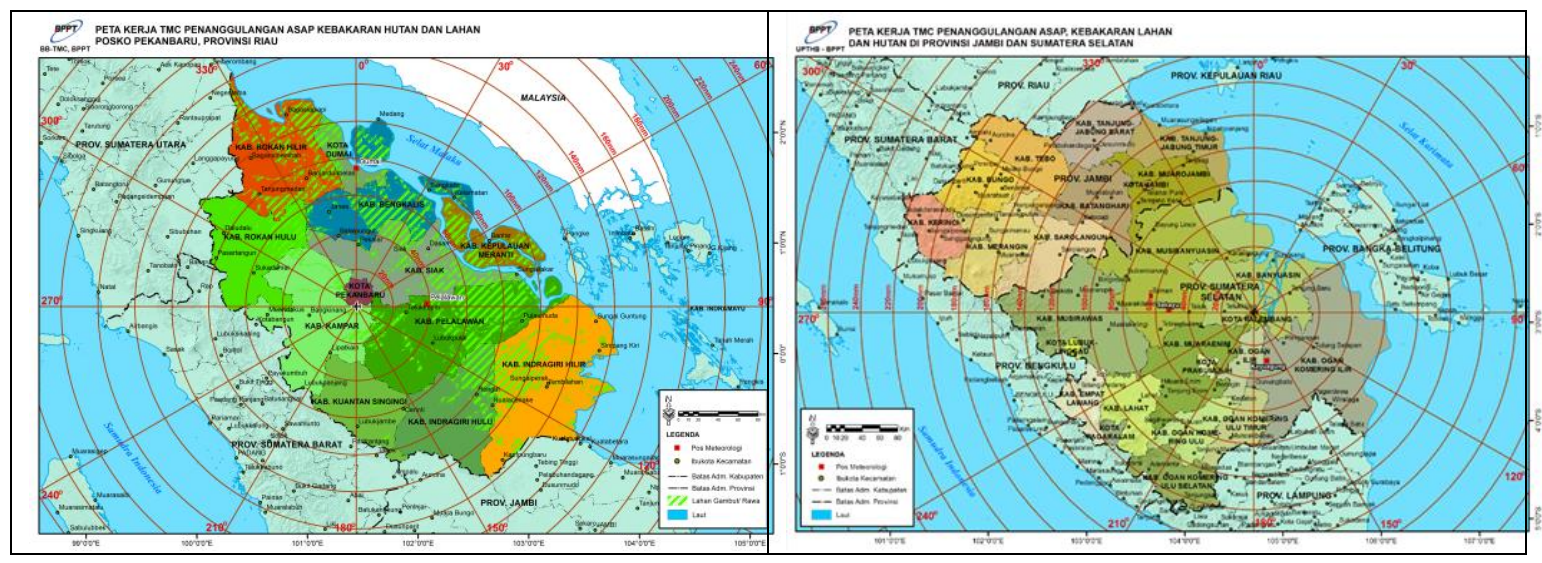

Gambar 1: Peta Kerja Operasionl TMC 


\section{HASIL DAN PEMBAHASAN}

Dari hasil penelusuran data sekunder selalu terdapat kejadian kebakaran hutan dan lahan di Sumatera dari tahun ke tahun. Namun demikian untuk tahun 2020 tingkat kebakaran hutan dan lahan di Sumatera mengalami kecenderungan yang menurun (lihat Tabel 1)

Tabel 1. Luas Kebakaran Hutan dan Lahan (Ha) per Provinsi di Sumatera, tahun 2015 - 2020

\begin{tabular}{|c|c|c|c|c|c|c|c|}
\hline No. & Provinsi & 2015 & 2016 & 2017 & 2018 & 2019 & 2020 \\
\hline 1. & Aceh & 913,27 & $9.158,45$ & $3.865,16$ & $1.284,70$ & 730 & 938 \\
\hline 2. & Riau & $183.808,59$ & $85.219,51$ & 6.8 & $37.236,27$ & 90.550 & 14.939 \\
\hline 3. & Jambi & 115.6 & $8.281,25$ & 109 & 1.577 & 56.5 & 262 \\
\hline 4. & $\begin{array}{l}\text { Sumatera } \\
\text { Selatan }\end{array}$ & 646.2 & $8.784,91$ & 3.62 & 16.22 & 336.798 & 678 \\
\hline 5. & $\begin{array}{l}\text { Sumatera } \\
\text { Utara }\end{array}$ & $6.010,92$ & $33.028,62$ & 767,98 & $3.678,79$ & 2.514 & 1.907 \\
\hline 6. & $\begin{array}{l}\text { Sumatera } \\
\text { Barat }\end{array}$ & $3.940,14$ & $2.629,82$ & $2.227,43$ & $2.421,90$ & 2.133 & 968 \\
\hline
\end{tabular}

\section{Sumber: Hasil Observasi Lapangan, 2020}

\section{a. Hasil Data Curah Hujan}

Hasil operasional Teknologi Modifiaksi Cuaca (TMC) dapat diindikasikan dengan hasil curah hujan yang turun dari hasil penyemaian awan. Curah hujan diukur dengan penakar curah hujan yang dimiliki oleh Badan Meteorologi, Klimatologi dan Geofisika atau disebut dengan BMKG, sehingga diperoleh grafik curah hujan di Provinsi Jambi dan Provinsi Sumatera Selatan, sedangkan untuk wilayah Riau masih dalam pantauan,

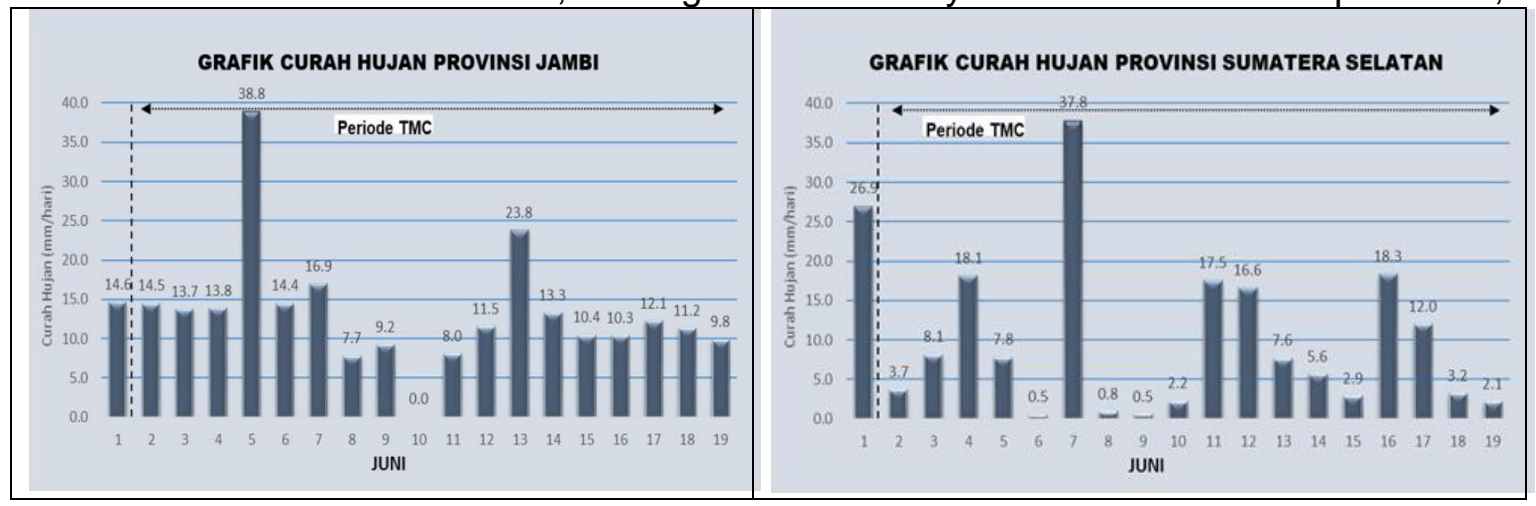

Gambar 2. Grafik Curah Hujan Provinsi Jambi dan Sumatera Selatan

Pada periode kegiatan 1-19 Juni 2020 di wilayah Provinsi Jambi maupun Sumatera Selatan hampir setiap hari terpantau adanya kejadian hujan. Curah hujan tertinggi untuk Provinsi Jambi sebesar $38.8 \mathrm{~mm}$ yang terjadi pada tanggal 5 juni 2020 dan Provinsi Sumatera Selatan sebesar $37,8 \mathrm{~mm}$ yang terjadia pada tanggal 7 Juni 2020. (lihat Gambar 2). Volume air hujan hasil Teknologi Modifiaksi Cuaca dihitung berdasarkan ketebalan hujan yang terukur pada satelit TRMM selama periode pelaksanaan Teknologi Modifiaksi Cuaca dikalikan dengan luas wilayah yang terpengaruh oleh aktifitas penyemaian Teknologi Modifiaksi Cuaca di lokasi target. Sehingga diperoleh data bahwa volume air hujan hasil Teknologi Modifiaksi Cuaca di Provinsi Riau (13-31 Mei) sebanyak 44,1 juta $\mathrm{m}^{3}$, sedangkan untuk Provinsi Jambi dan Sumatera Selatan sebanyak 50,20 juta $\mathrm{m}^{3}$.

\section{b. Hotspot}

Perbandingan total hotspot tahun 2019 dan 2020 diketahui bahwa mulai tanggal 1 Januari sd 4 Agustus 2020 berdasar pada satelit Terra/Aqua (NASA) dengan tingkat 
confidence $>80$ terdapat 1.044 titik, sedang pada periode yang saya pada tahun 2019 terdapat 2.518 titik (Data dari Satelit Terra/Aqua tahun 2020 sampai tanggal 4 Agustus 2020, pukul 07.00 WIB). Dengan demikian, maka terdapat penurunan sebanyak 58,54 $\%$ dibanding periode sebelumnya. Hal ini mengindikasikan bahwa mitigasi untuk pencegahan kebakaran hutan dan lahan yang dilakukan lebih dini sebelum terjadi kebakaran yang masih sangat efektif.
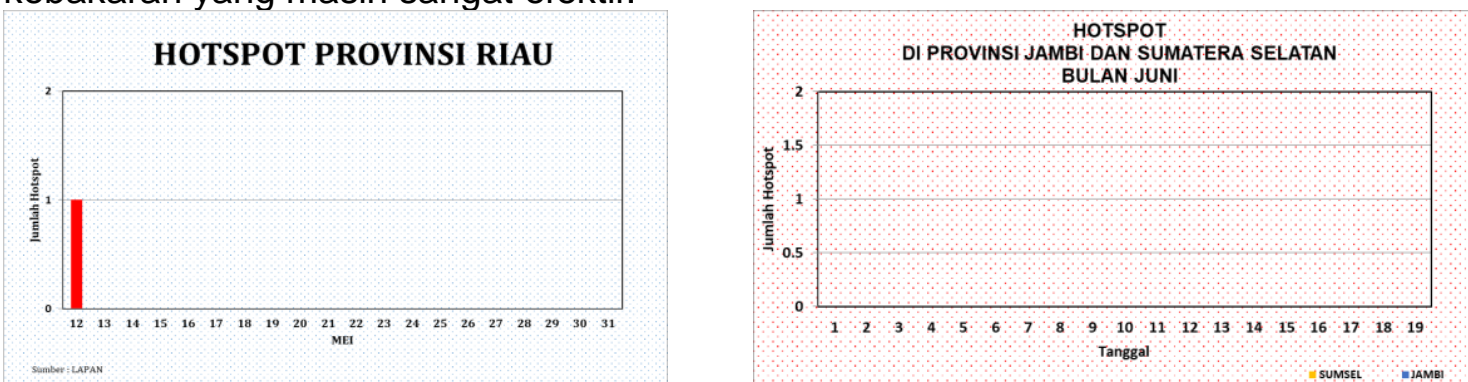

Gambar 3. Kondisi Hotspot Provinsi Riau, Jambi dan Sumatera Selatan

Dari gambar 3 tersebut dapat dijelaskan bahwa selama pelaksanaan teknologi Modifikasi pencegahan risiko kebakaran hutan dan lahan dapat ditangani dengan baik. Hal ini dapat menunjukkan bahwa selama pelaksanaan Teknologi Modifiaksi Cuaca (TMC) dapat menjaga titik panas (hotspot) yang terjadi di wilayah penelitian, sedangkan untuk tingkat kepercayaaan $>80 \%$ sebanyak nol atau nihil. Dengan demikian , maka efektivitas pencegahan kebakaran hutan dan lahan dengan Teknologi Modifiaksi Cuaca dapat dilakukan secara efektif yaitu dapat mereduksi risiko kebakaran hutan dan lahan yang masip (lihat Gambar 3).

\section{c. Tinggi Muka Air Tanah Lahan Gambut}

Selain informasi curah hujan dan titik panas (Hotspot), selama pelaksanaan kegiatan Teknologi Modifiaksi Cuaca (TMC) juga dilakukan pemantauan/pengamatan tinggi muka air tanah (TMAT) gambut pada jam 07.00 WIB dari situs SIPALAGA. Berikut grafik TMA di beberapa kabupaten di Provinsi Riau, Provinsi Jambi dan Provinsi Sumatera Selatan. Dari hasil pemantauan TMAT yang ada di Provinsi Riau sebanyak 9 tempat bahwa TMAT dapat terjaga dengan baik dapat mempertahankan TMA $-0,40 \mathrm{~cm}$. hasil pantauan dapat ditunjukkan pada gambar 4

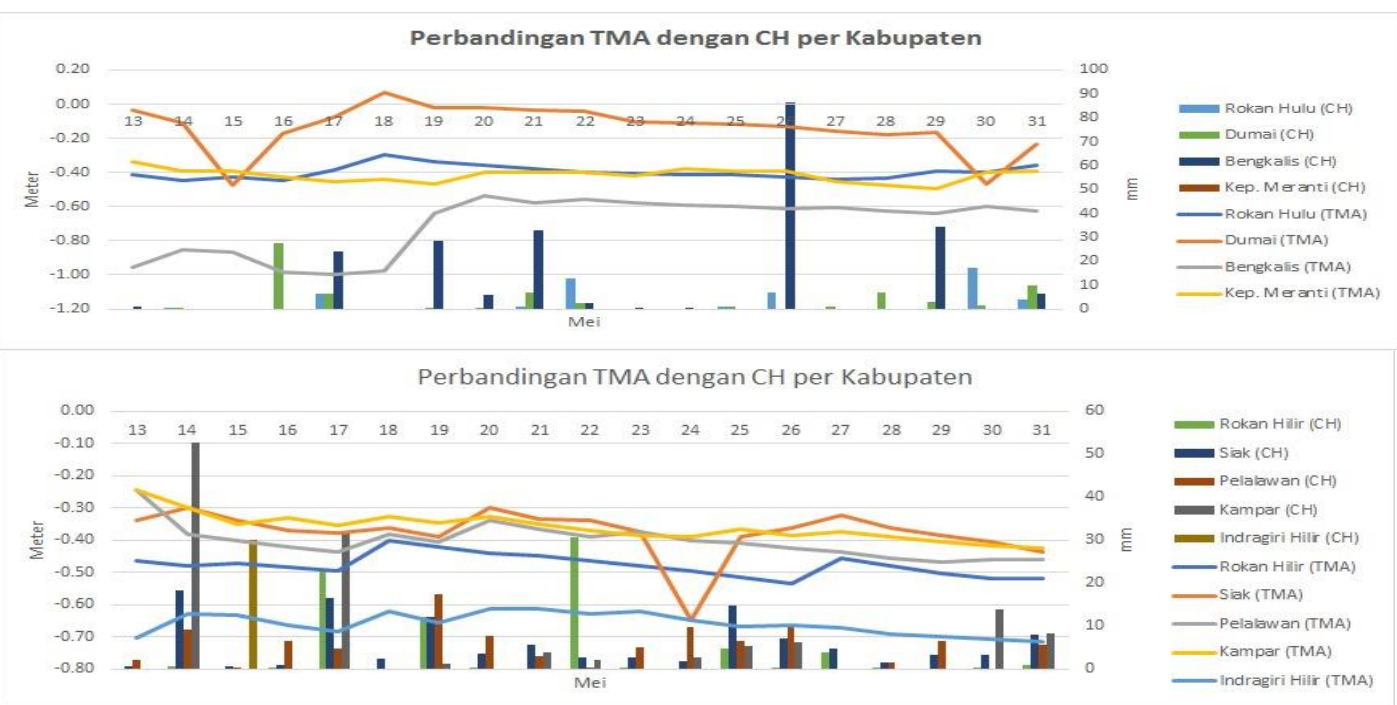

Gambar 4. Trend Tinggi Muka Air Tanah Lahan Gambut di Provinsi Riau 
Pada gambar grafik 4 dapat diketahui bahwa 3 (tiga) kabupaten dengan ketinggian TMA yang dapat dipertahankan pada kondisi di atas batas bahaya -0.4 meter yaitu Kabupaten Rokan Hulu, Kabupaten Dumai dan Kabupaten Kepulauan Meranti. Sedangkan pada Kabupaten Bengkalis yang mengalami kenaikan cukup signifikan pada akhir masa Teknologi Modifiaksi Cuaca (TMC) dibandingkan pada awal masa Teknologi Modifiaksi Cuaca (TMC).

Sedang dari hasil pemantauan dan monitoring tinggi muka air tanah lahan gambut untuk wilayah Provinsi Jambi yang ada di TMA Stasiun Kabupaten Tanjung Jabung barat dan Tanjung Jabung Timur seperti pada gambar 5

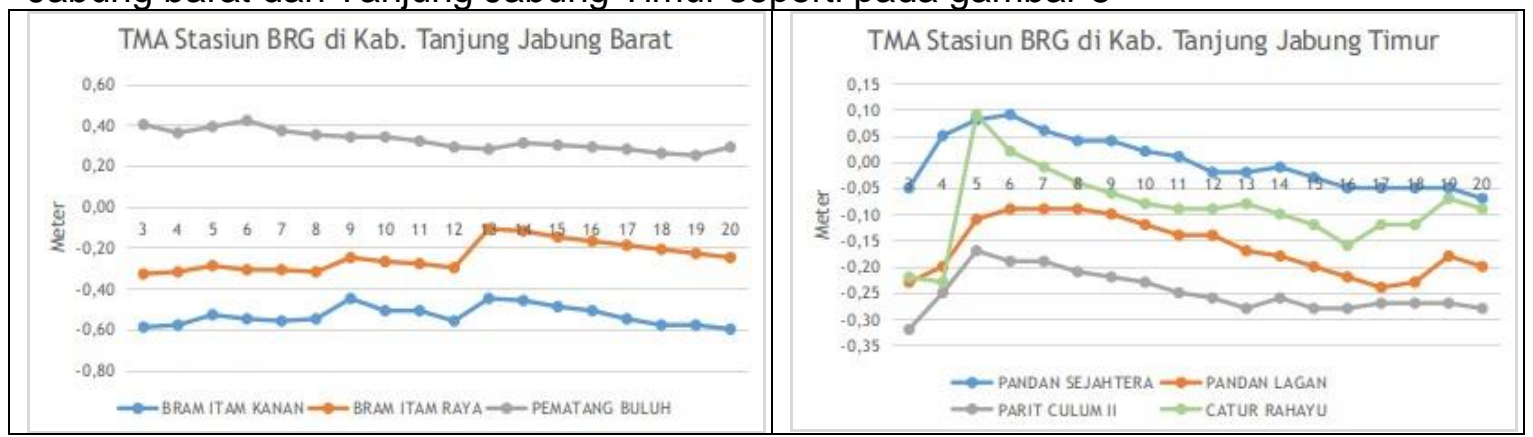

Gambar 5. Stasiun Pos Pantauan TMA di Provinsi Jambi.

Berdasar hasil pemantauan selama kegiatan Teknologi Modifiaksi Cuaca (TMC) dapat dipantau bahwa dari 7 lokasi pengamatan ada 5 lokasi terjadi kenaiakan TMA dan 2 lokasi terjadi penurunan yaitu di pos pemantau Pematang Buluh dan pos pemantau Pandan Sejahtera. Namun demikian penurunannya tidak signifikan. Selanjutnya pantauan dari satsiun BRG yang ada di Sumatera Selatan dipantau sebanyak 5 titik pengamatan secara umum TMA meningkat mulai awal kegiatan sampai akhir kegiatan oprasional TMC (lihat Gambar 6)

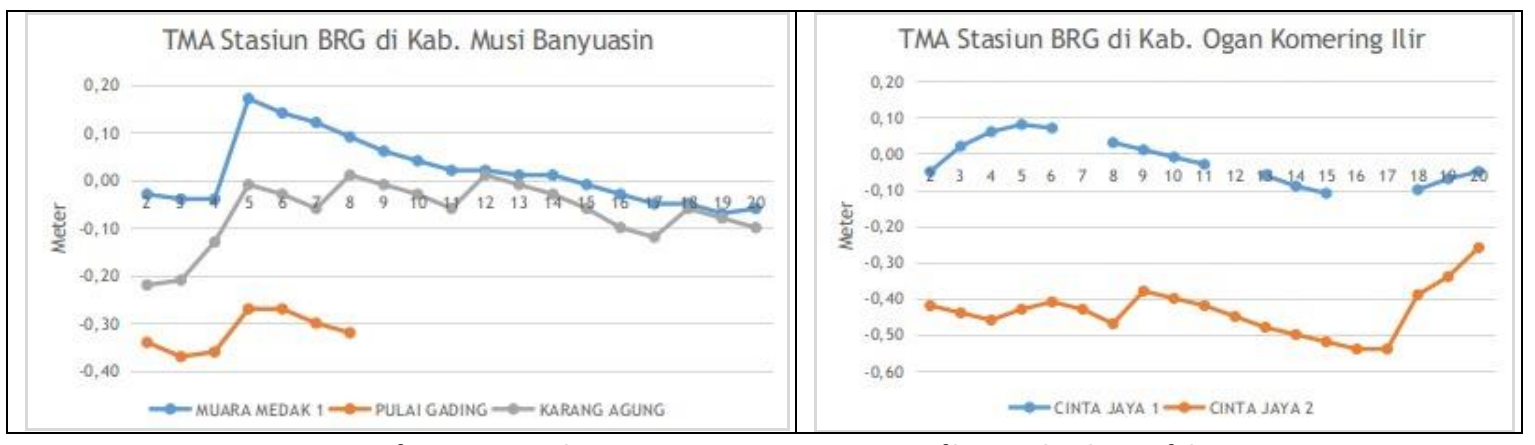

Gambar 6: Stasiun Pos Pantauan TMA di Provinsi Jambi.

Dari pantauan TMA yang mengalami peningkatan adalah di Stasiun Cinta Jaya 2 dan Karang Agung. Kondisi ini menujukkan bahwa beberapa lokasi stasiun dapat mereduksi risiko terjadinya kemudahan terbakar karena kelembaban air tanah yang cukup basah.

\section{SIMPULAN}

Dari beberapa pembahasan hasil penelitian tesebut dapat disimpulkan beberapa hal sebagai berikut:

1. Mitigasi Risiko bencana Karhutla di wilayah Provinsi Riau, Jambi dan Sumatera Selatan selama kegiatan TMC terjadi hujan hampir setiap hari dengan intensitas hujan hujan ringan hingga hujan sedang. 
2. Volume air hujan yang dihasilkan untuk Riau sebanyak 44,1 juta $\mathrm{m}^{3}$ dan di Jambi dan Sumatera Selatan sebanyak 50,20 juta $\mathrm{m}^{3}$.

3. TMC dapat meningkatan intensitas curah hujan di daerah target untuk membasahi lahan gambut dan mengisi kubah gambut agar terjaga TMAT (Tinggi Muka Air Tanah) sehingga mengurangi faktor pemicu muncul hotspot baru.

4. Trend Tinggi Muka Air Tanah (TMAT) gambut secara umum tidak mengalami penurunan yang signifikan dan bahkan untuk TMAT di Provinsi Jambi dan Sumatera Selatan terjadi peningkatan.

\section{DAFTAR PUSTAKA}

BBTMC (2020), Laporan Kegiatan Pemanfaatan Teknologi Modifikasi Cuaca untuk Menanggulangi Bencana Asap Kebakaran Hutan dan Lahan di Sumatera Selatan dan Jambi 2020.

Dwi Hadya Jayani, (2019). Tren kebakaran hutan dan lahan 2009-2019. Data boks online. Diakses dari: Databoks.katadata.co.id

Ernoiz Antriyandarti et al (2019). J. Phys.: Conf. Ser. 1153 012131. Mitigation of Peatland Fires and Haze Disaster Through Livelihood Revitalization: A Case Study in Pelalawan Riau.

Shearman, David, (2007). The Climate Change Challenge and the Failure of Democracy, Westport: Praeger Publishers.

----------, https://republika.co.id/berita/pyqrv6370/modifikasi-cuaca-bantu-turunkan-titikpanas.

Tim Publikasi Kata Data,(2019). Luas Gambut Indonesia Terbesar ke dua Didunia. Katadata.co.id online. Diakses dari: katadata.co.id 